International Journal of Engineering \& Technology, $7(3.2)(2018) 306-310$
International Journal of Engineering \& Technology
SPC
Website: www.sciencepubco.com/index.php/IJET
Research paper

\title{
Application of Effective Microorganisms in Soil-Cement Mixtures
}

\author{
Oleksandr Petrash ${ }^{1}$, Ruslan Petrash ${ }^{2}$, Nataliia Popovych ${ }^{3}$

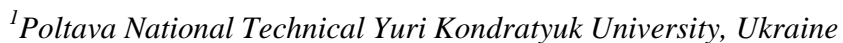 \\ ${ }^{2}$ Poltava National Technical Yuri Kondratyuk University, Ukraine \\ ${ }^{3}$ Poltava National Technical Yuri Kondratyuk University, Ukraine \\ *Corresponding Author E-Mail: Alexandr_Petrash@Ukr.Net
}

\begin{abstract}
This paper provides a research data on the impact of effective microorganisms on the physic and mechanical properties of soil-cement mixtures and stone. Deep soil mixing technology considered to be used for manufacturing soil-cement. The purpose of the research is to determine a way of increasing strength of soil-cement by addition of effective microorganisms. Strength increasing method should not compromise the mixture's movability. Authors used an experimental approach within which there were standard techniques of determining the movability of soil-cement mixture and density and strength of a soil-cement stone in a laboratory environment. This research resulted in discovering the optimal contents of a soil-cement mixture with respect to mechanical properties required. Authors proved the effective microorganisms to be efficient mean of increasing the strength of soil-cement.
\end{abstract}

Keywords: density; effective microorganisms; movability; Poltava loess plateau; soil-cement; strength.

\section{Introduction}

Soil-cement is a composite, stone-like material composed of a local soil mixed with water, cement, and a plasticizer into a homogeneous mixture containing no coarse-grained fraction. Soilcement mixtures are utilized for manufacturing soil reinforcing elements, waterproof walls, piles, and roads base $[1,2]$.

The mixtures are always manufactured directly on a site by respective equipment and served as a structural material after hardening into soil-cement stone. Deep soil mixing (DSM) technology is often utilized for soil-cement manufacturing (fig. 1).

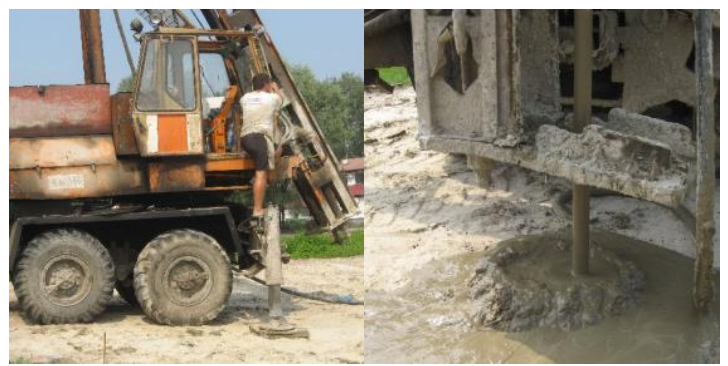

Fig. 1: Deep soil mixing technology of manufacturing the soil-cement elements: drilling rig deploys supports and tower; drilling tube goes down to designed depth with a simultaneous water-cement mixture supply through the drilling bit; after the designed depth is reached a mixture supplying shuts down and drilling tube keeps mixing soil-cement along the height of an element until its homogeneity is reached.

Only Portland cement and chemical additives are transported, while soil and water available on a construction site. Apart from structural and technological features, the main advantage of soilcement mixture is its low cost and economical consumption of resources needed [3].
Another characteristic feature of soil-cement is that its efficient exploitation is possible below water table only (fig. 2). In this water-saturated environment, soil-cement structures gain a proper strength and deformation characteristics. That brings up another peculiarity of soil-cement mixtures' high movability.

However, above-mentioned conditions are beneficial for DSM technology. When heavy clays are encountered there's a high possibility of drilling equipment to be stuck underground and the only way to avoid that is having enough water in the soil-cement mixture.

Nevertheless, a significant disadvantage of soil-cement stone is a low value of mechanical strength. Given the modern Ukrainian technological level and soil-cement application field, it's hard to obtain a soil-cement stone with a strength higher than $3-4 \mathrm{MPa}$ [4]. Under described conditions, the actual task is to find a way of increasing soil-cement strength that would fit into DSM technology and wouldn't increase the work cost dramatically.

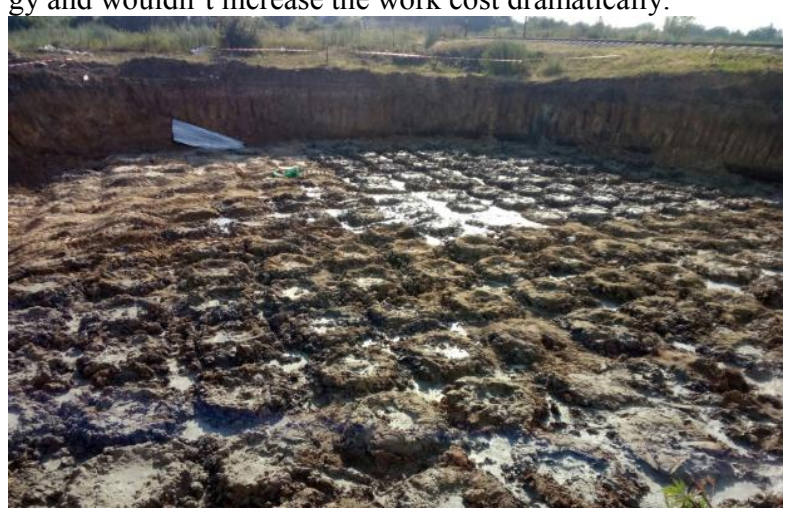

Fig. 2: A block of soil-cement piles for industrial facility's foundation with high level of water table 
This research addresses the issue of designing a soil-cement mixture composition with an optimal strength/movability/density ratio utilizing effective microorganisms.

\section{Main Body}

In this research, a soil-cement mixture was manufactured in a laboratory environment. Soil-cement mixture was manufactured by mixing loess loam, Portland cement, water, and effective microorganisms (EM additive) in a form of ceramic powder. EM additive was mixed with Portland cement and water. This mixture was introduced into the loess loam and again mixed until the homogeneity reached.

Mixture composition designing proceeds as follows:

1 . Knowing the volume $V$ of soil-cement to be manufactured, it's necessary to calculate the mass $m$ of soil in that volume by multiplying it by undisturbed soil density $\rho$;

2. Using soil wetness $W$, calculate the weight of a completely dry soil as $m d=m /(1+W)$;

3 . The cement mass $C$ is calculated as a percent of the weight of completely dry soil mass;

4. Then a water/cement ratio $(W / C)$ is set based on mixture's movability needed;

5. Amount of the water needed was calculated as a product of $C \times W / C$, from which the water that is already in the soil (m-md) must be subtracted;

6. Mass of EM additive was calculated as a percent of cement mass.

\subsection{Experiment Planning}

There were prepared and tested 18 different compositions of soilcement with 6 samples within each of them. Table 1 contains a plan of the experiment.

The first series of 9 compositions was to reveal general tendencies of EM additive interaction with the amount of cement and water used, and its influence on strength, movability, and density. The cement content here was constant $-20 \%$. The variable parameters $\mathrm{X} 1$ and $\mathrm{X} 2$ were the amount of EM additive and W/C respectively. Having an optimal water-cement ratio, the second series of 9 compositions were used to discover the amount of EM additive that provides the best impact on the mentioned above mechanical properties of soil-cement. The variables here were the amount of cement and EM additive.

Table 1: Soil-cement compositions

\begin{tabular}{|c|c|c|c|c|c|c|}
\hline \multirow{2}{*}{$\begin{array}{c}\text { Composition } \\
\text { No. }\end{array}$} & \multicolumn{2}{|c|}{ Variables } & \multicolumn{2}{c|}{ First series } & \multicolumn{2}{c|}{ Second series } \\
\cline { 2 - 7 } & $\mathrm{X}_{1}$ & $\mathrm{X}_{2}$ & $\mathrm{EM}$ & W/C & $\mathrm{C}$ & EM \\
\hline 1 & 1 & 1 & 3 & 2.7 & 30 & 6 \\
\hline 2 & 1 & -1 & 3 & 2.3 & 30 & 2 \\
\hline 3 & -1 & 1 & 1 & 2.7 & 10 & 6 \\
\hline 4 & -1 & -1 & 1 & 2.3 & 10 & 2 \\
\hline 5 & 1 & 0 & 3 & 2.5 & 30 & 4 \\
\hline 6 & -1 & 0 & 1 & 2.5 & 10 & 4 \\
\hline 7 & 0 & 1 & 2 & 2.7 & 20 & 6 \\
\hline 8 & 0 & -1 & 2 & 2.3 & 20 & 2 \\
\hline 9 & 0 & 0 & 2 & 2.5 & 20 & 4 \\
\hline
\end{tabular}

Thus, all the compositions had the same components but in different quantities.

\subsection{Raw Materials}

There were following materials used for conducting this research.

1. The soil was a loess loam, light brown, its wetness was $6.5 \%$, plasticity $I_{P}=15 \%$, porosity $47 \%$, and deformation module $4 \mathrm{MPa}$. The soil source was Poltava loess plateau. The soil samples were taken from the depth of $8 \mathrm{~m}$. The soil natural wetness was preserved until the time of soil-cement manufacturing.

2. Portland cement grade 400 that fits general construction needs according to National standard DSTU B V. 2.7-46-96 [5]. According to the document, it's type II cement with additives (6-
$35 \%$ of mineral additives, $21-35 \%$ of slag, $0-5 \%$ additional components, and $65-79 \%$ of clinker)

3. Freshwater with $\mathrm{Ph}$ indicator 8 . The water met the necessary requirements of ISO 3696:2003 [6].

4. EM additive.

Since soil-cement contains no coarse-grained fraction (fig. 3), in this research it is treated as a mixture, and common standards [7] for assessing mechanical properties of construction mixtures were used. All the used materials corresponded to Ukrainian national standards.

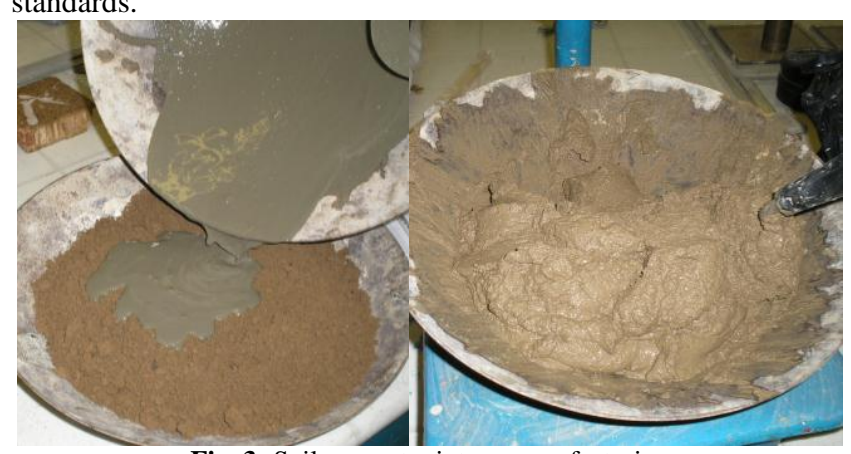

Fig. 3: Soil-cement mixture manufacturing

\subsection{Results}

All the tests conducted in accordance with the experiment's plan using mathematical and statistic methods of data treatment. All specimens had a cubic shape with the size of $70.7 \mathrm{~mm}$. The specimens hardened in water saturated environment 28 days. After this period of time the specimens were expected to gain it's designed strength.

It's desirable to discover the composition where EM additive has the positive effect on soil-cement strength and movability both.

The impact of EM additive content on the density of soil-cement is illustrated by fig. 4 .

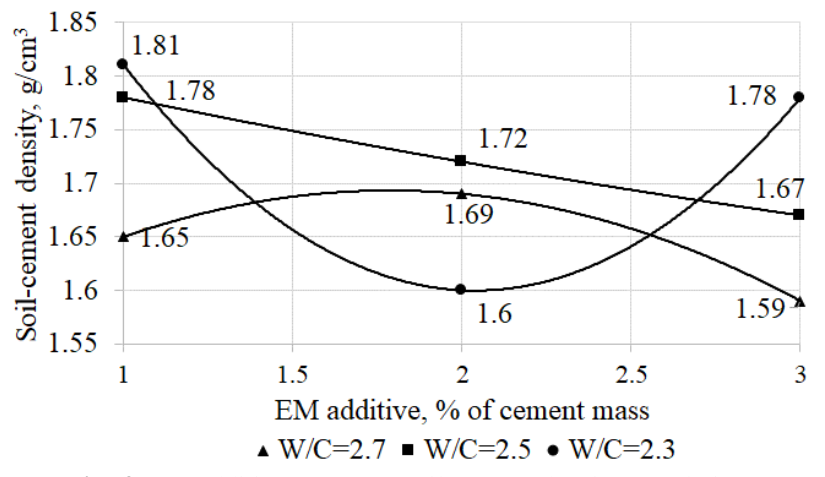

Fig. 4: EM additive content - soil-cement density correlation

After a computer processing of experimental data, the soil-cement density is given by:

$Y_{\text {density }}=1.67-0.025 X_{1}-0.043 X_{2}-0.007 X_{1} X_{2}$

Judging from figure 1, it's clear that EM additive decreases soilcement density when using W/C ratio of 2.5 and 2.7. The exception here is the density of a mixture with $\mathrm{W} / \mathrm{C}$ ratio of 2.3 but this kind of mixture isn't often applied in DSM technology and is of minor interest.

If the suggestion is true, the EM additive should increase the movability of soil-cement. This feature is crucial for the ability of a drilling rig to manufacture a homogeneous soil-cement stone. The movability of soil-cement was estimated using standard cone settle method (fig. 5). 


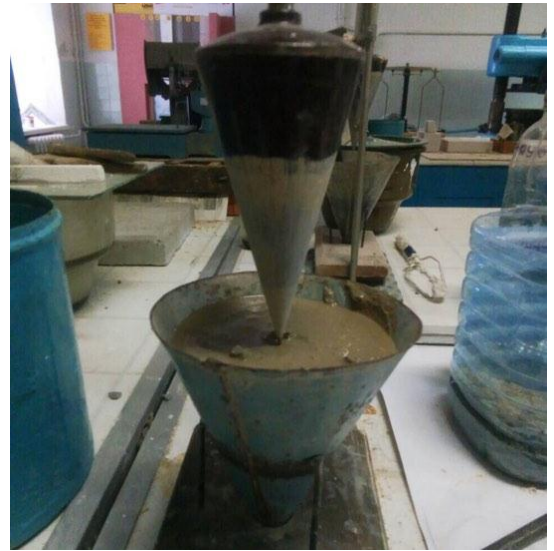

Fig. 5: Determination of soil-cement movability by standard cone settle method

The correlation between EM additive content and soil-cement movability is depicted in fig. 6 .

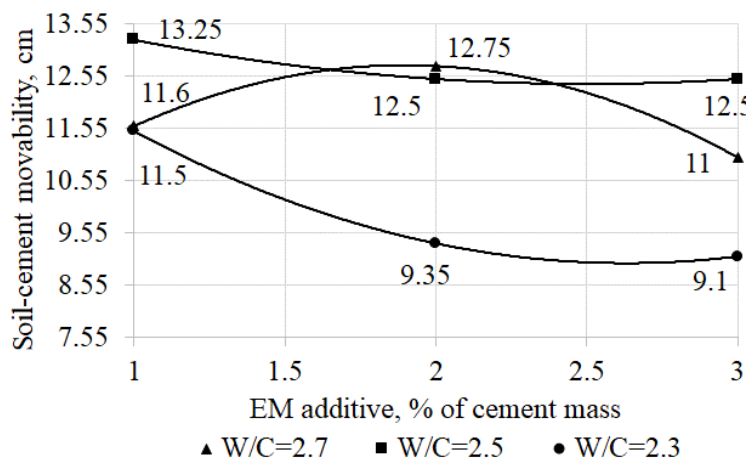

Fig. 6: EM additive content - soil-cement movability correlation

Analysis of fig. 6 shows that the increasing of soil-cement movability was observed only when $\mathrm{W} / \mathrm{C}=2.7$. The other curves show no positive effect of EM additive on soil-cement movability However, the positive effect vanishes when the additive dosage exceeds $2 \%$. The equation of soil-cement movability is as follows:

$$
Y_{\text {movability }}=12.31-0.61 X_{1}+0.188 X_{2}-0.45 X_{1} X_{2}
$$

The most important piece of data concerns the EM additive impact on the strength of soil-cement. The strength determination process is depicted in fig. 7.

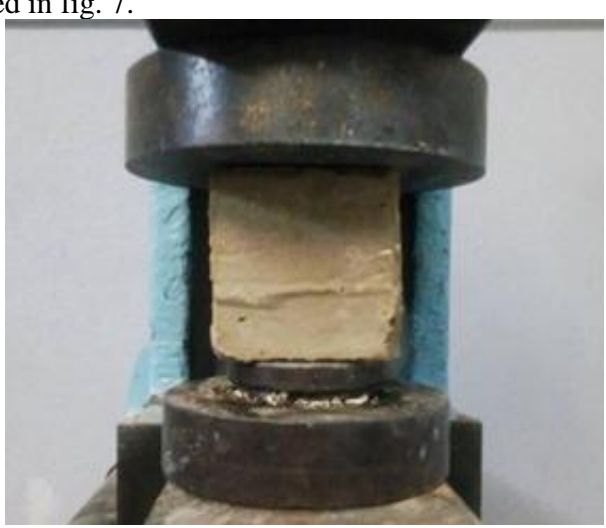

Fig. 7: Determination of soil-cement strength

The correlation between EM additive content and soil-cement movability is depicted in fig. 8 .

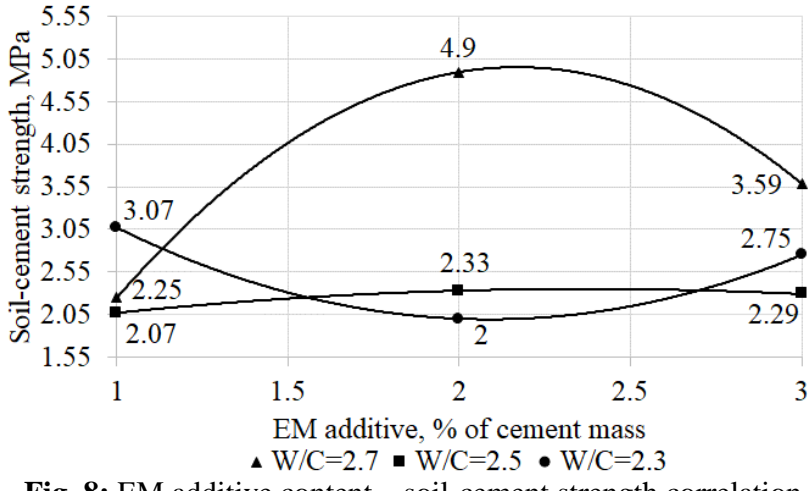

Fig. 8: EM additive content - soil-cement strength correlation

The latter curves obviously show that EM additive has the positive effect on strength of soil-cement. However, the effect depends on the $\mathrm{W} / \mathrm{C}$ ratio of a mixture. Thus, the significant increase in the strength of soil-cement is possible to obtain using "wet" or high movable soil-cement mixtures with $\mathrm{W} / \mathrm{C}$ ratio of 2.7 . That fact justifies the use of EM additives in soil-cement manufactured by DSM technology where it's nearly impossible to work with mixtures of lower than $2.7 \mathrm{~W} / \mathrm{C}$ ratio. The soil-cement strength in this experiment is given by:

$$
Y_{\text {strength }}=24.51-2.13 X_{1}+4.88 X_{2}+4.13 X_{1} X_{2}
$$

The overall research results of the first series of experiment is presented in table 2 for further analysis.

Table 2: Research results (first series)

\begin{tabular}{|c|c|c|c|c|c|}
\hline $\begin{array}{c}\text { Composition } \\
\text { No. }\end{array}$ & EM, \% & W/C & $\begin{array}{c}\text { Density, } \\
\mathrm{g} / \mathrm{cm}^{3}\end{array}$ & $\begin{array}{c}\text { Movability, } \\
\mathrm{cm}\end{array}$ & $\begin{array}{c}\text { Strength, } \\
\mathrm{MPa}\end{array}$ \\
\hline 1 & 1 & 2.7 & 1.65 & 11.6 & 2.3 \\
\hline 2 & 2 & 2.7 & 1.69 & 12.8 & 4.9 \\
\hline 3 & 3 & 2.7 & 1.59 & 11.0 & 3.6 \\
\hline 4 & 1 & 2.5 & 1.78 & 13.3 & 2.1 \\
\hline 5 & 2 & 2.5 & 1.72 & 12.5 & 2.3 \\
\hline 6 & 3 & 2.5 & 1.67 & 12.5 & 2.3 \\
\hline 7 & 1 & 2.3 & 1.81 & 11.5 & 3.1 \\
\hline 8 & 2 & 2.3 & 1.60 & 9.4 & 2.0 \\
\hline 9 & 3 & 2.3 & 1.78 & 9.1 & 2.8 \\
\hline
\end{tabular}

The above stated data proves the necessity of further research of soil-cement's physical and mechanical properties in the second series of experiments (see table 1). At this point, it's necessary to investigate if there is a possibility to gain higher values of strength by varying the cement and EM additive contents.

In the following research part, water/cement ratio remained constant -2.7 as the optimal value from the previous experience., The amount of EM additive, in turn, varied from 2 to $6 \%$ of cement mass. The cement mass itself varied between 10 and $30 \%$ of a dry soil mass.

The correlation between EM additive content and soil-cement density is presented in fig. 9 .

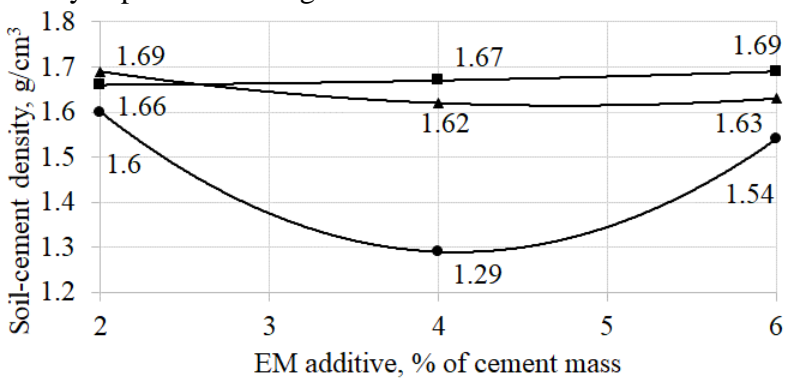

\ Cement $10 \%$ of $\mathrm{md}$ - Cement $20 \%$ of md $\bullet$ Cement $30 \%$ of md

Fig. 9: EM additive content - soil-cement density correlation An equation describing the density is:

$Y_{\text {density }}=1.62-0.08 X_{1}-0.015 X_{2}$ 
Fig. 8 shows that the additive has no significant effect on soilcement density when cement content is low (10\% and $20 \%)$. On the other hand, at the maximum value of cement content $(30 \%)$ the additive impacts density dramatically: $22 \%$ decreasing of density at $4 \%$ of the additive content.

To assess the latter results correctly the influence of the additive on soil-cement movability (fig. 10) must be analyzed.

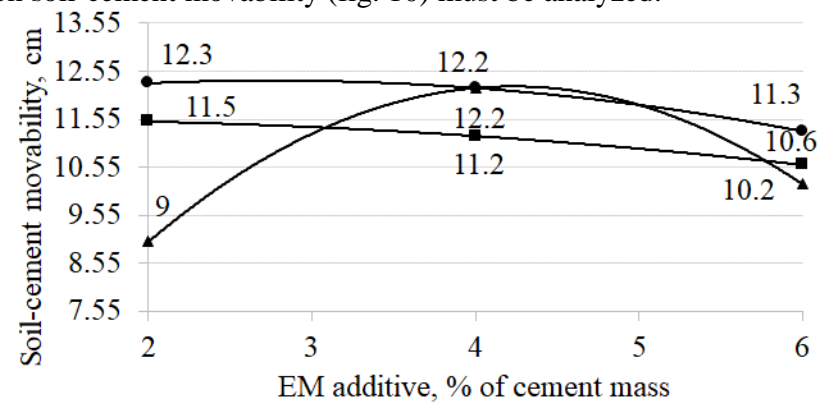

\ Cement $10 \%$ of md $\bullet$ Cement $20 \%$ of md $\bullet$ Cement $30 \%$ of md Fig. 10: EM additive content - soil-cement movability correlation

The latter results correspond the former: the expected increases in movability is reached at the lowest level of cement content (10\%) while the previous diagram showed decreasing in density here. The peculiar moment is that at the maximum level of cement content $(30 \%)$ the movability shows a stable decrease while the density decreases also but only to the mark of $4 \%$ of additive, followed by the increase to practically initial level.

The soil-cement movability in the second part of the experiment given by:

$Y_{\text {movability }}=10.2-0.57 X_{1}+0.152 X_{2}-0.3 X_{1} X_{2}$

The analysis of EM additive impact on soil-cement strength (fig. 11) allows making a justified conclusion on the second part of the experiment.

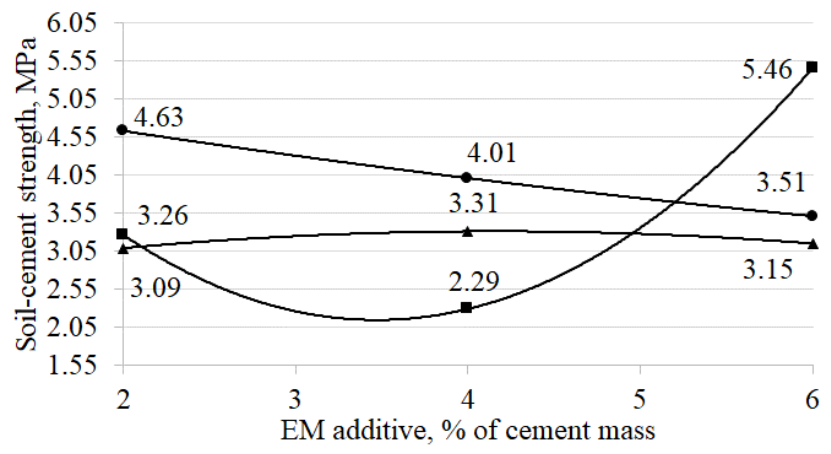

\ Cement $10 \%$ of md - Cement $20 \%$ of md $\bullet$ Cement $30 \%$ of md

Fig. 11: EM additive content - soil-cement strength correlation

The last diagram allows concluding that the additive has no positive effect on strength when the cement content is $10 \%$ and $30 \%$. The significant effect (67\% of strength increasing) is reached when the cement content is $20 \%$ and the mass of additive is $6 \%$ of it. The strength here is significantly higher than in the samples that had $50 \%$ more of cement.

That correlates with fig. 10 and fig. 9 where this mixture composition showed increasing in density and respective slight decreasing in movability.

The equation of soil-cement strength is the following:

$Y_{\text {strength }}=28.49+4.33 X_{1}+1.89 X_{2}-2.95 X_{1} X_{2}$

The second series of experiments allows concluding that at the optimal W/C of 2.7 the optimum amount of cement is $20 \%$ of the dry soil mass. The EM additive content that provides the best effect is $6 \%$ of cement mass.
The overall research results of the second series of experiment is presented in table 3 for further analysis.

Table 3: Research results (second series)

\begin{tabular}{|c|c|c|c|c|c|}
\hline $\begin{array}{c}\text { Composition } \\
\text { No. }\end{array}$ & EM, \% & $\mathrm{C}, \%$ & $\begin{array}{c}\text { Density, } \\
\mathrm{g} / \mathrm{cm}^{3}\end{array}$ & $\begin{array}{c}\text { Movability, } \\
\mathrm{cm}\end{array}$ & $\begin{array}{c}\text { Strength, } \\
\mathrm{MPa}\end{array}$ \\
\hline 1 & 2 & 10 & 1.69 & 9 & 3.09 \\
\hline 2 & 4 & 10 & 1.62 & 12.2 & 3.31 \\
\hline 3 & 6 & 10 & 1.63 & 10.2 & 3.15 \\
\hline 4 & 2 & 20 & 1.66 & 11.5 & 3.26 \\
\hline 5 & 4 & 20 & 1.67 & 11.2 & 2.29 \\
\hline 6 & 6 & 20 & 1.69 & 10.6 & 5.46 \\
\hline 7 & 2 & 30 & 1.6 & 12.3 & 4.63 \\
\hline 8 & 4 & 30 & 1.29 & 12.2 & 4.01 \\
\hline 9 & 6 & 30 & 1.54 & 11.3 & 3.51 \\
\hline
\end{tabular}

The effect from additive application is better compared to cement content increasing. However, it's not recommended to drop the cement content lower than $20 \%$. The combined results of two experimental series confirm the practical manufacturing experience of thousands $\mathrm{m}^{3}$ of soil-cement underground structures in Poltava and other Ukrainian regions [8 - 12].

The obtained optimal soil-cement mixture composition presented here has been used in a variety of cases and proved to be efficient in loess soils that underlie nearly $70 \%$ of a flat area of Ukraine. The main issues were a low strength of soil-cement and its incapability to operate outside of the water-saturated environment. Thus, soil-cement is recommended to be used for underground structures with a high level of water table.

Application of EM additive can help improving the mechanical features of soil-cement, its strength, in particular, manufactured by DSM technology.

The provided data on movability of soil-cement show that the proposed mixture compositions are completely in range of technical capabilities of the equipment used for its manufacturing in Ukraine.

\subsection{Discussion}

There is some ambiguity in test results. Fig. 11 and fig. 8 show the EM additive-strength correlation: the curvatures of samples that showed the highest strength have different directions. That fact requires further investigation.

In the following research, it's recommended to calculate the amount of EM additive as a percent of a dry soil mass. So that the amount of additive wouldn't depend on the amount of cement.

The presented results were obtained in laboratory conditions and still need a field confirmation where the scale of soil-cement structures is different and inhomogeneity might occur.

The EM additive impact on soil-cement properties in long time perspective is worth investigating since there isn't much data on that issue, in particular, the impact of temperature changes on mechanical properties of soil-cement during day/night cycle, as well as during seasons change.

The significant impact of $6 \%$ of the additive on soil-cement strength might actually be the increasing of the hardening speed of soil-cement. For that reason, the investigation of gaining strength process by soil-cement in time is the actual task for further research.

The positive effect on mechanical properties of soil-cement as the structural material allows the optimization of soil-cement foundation designs. Thus, the economic effect of EM additive is worth further investigation.

\section{Conclusion}

This article has proved the soil-cement with $20 \%$ of cement and $\mathrm{W} / \mathrm{C}=2.7$ to be the optimal base composition compared to a number of other soil-cement mixtures with the different combinations of the mentioned above parameters 
The test results of density, movability, and strength of soil-cement have revealed the positive impact of EM additive.

EM additive increases soil-cement movability. Adding the $2 \%$ of the additive can increase the movability by $15-20 \%$ compared to an ordinary mixture. The higher values of the additive give no positive effect on movability. That effect can improve the quality and speed of soil-cement mixing process and also can be utilized during the process of dipping the steel reinforcing frame into the soil-cement piles.

The impact of the additive on the soil-cement density is corresponding to the impact on movability. Increasing in movability leads to respective decreasing in density and vice versa. When the amount of the additive ranges between $2 \%$ and $6 \%$ there is an observed increase in soil-cement density. Since there is a correlation between density, porosity, and the waterproof ability of soilcement, that fact justifies the usage of the additive in the manufacturing of underground waterproof screenings of soil-cement.

The higher values $(6 \%)$ of EM additive in this research had a positive effect on soil-cement strength. The strength of the base optimal soil-cement composition supplemented by $6 \%$ of EM additive is $25-30 \%$ higher than the base strength. In addition, the movability isn't affected in any way. This fact allows decreasing the total area of soil-cement piles without affecting the carrying capacity of a foundation.

This research has discovered that EM additive is a more efficient way of increasing soil-cement strength than simple increasing of cement mass in a mixture.

It's been discovered that EM additive shows the best effect applied in the optimal composition of soil-cement that is widely used by the construction industry of Poltava. Thus, EM additive is completely compatible with DSM technology of manufacturing the soil-cement underground structures.

The research results have revealed the possible variation in soilcement mixture compositions that would be favorable for different structural application of soil-cement. Thus, the used amount of EM additive can be set based on what mechanical feature of a soilcement mixture is of the essence in each particular case: density for water-proof screenings, strength for soil-cement elements, movability and strength for soil-cement piles.

\section{Acknowledgement}

Authors express gratitude to fellow scientists of Poltava National Technical Yuri Kondratyuk University - professor M.L. Zotsenko who provided raw materials and scientific guidance to this research and to associate professor V.V. Shulgin for support in manufacturing and testing procedures during the experiments.

\section{References}

[1] Daniel Ribeiro, Raquel Néri, Rafaela Cardoso, "Influence of Water Content in the UCS of Soil-Cement Mixtures for Different Cement Dosages", Procedia Engineering, Vol.143, (2016), pp.59-66, https://doi.org/10.1016/j.proeng.2016.06.008

[2] Ahmad Safuan A. Rashid, Jonathan A. Black, Ahmad Beng Hong Kueh, Norhazilan Md Noor, "Behaviour of weak soils reinforced with soil cement columns formed by the deep mixing method: Rigid and flexible footings", Measurement, Vol.68, (2015). pp.262279, https://doi.org/10.1016/j.measurement.2015.02.039

[3] Zotsenko M.L., Soil-Cement Piles Manufactured by Deep Soil Mixing Technology, Typografyya Madrid, (2016), pp:12-89. http://reposit.pntu.edu.ua/handle/PoltNTU/2062

[4] Xiao-nan Gong, Xiao-jun Tian, Wen-tao Hu, "Simplified method for predicating consolidation settlement of soft ground improved by floating soil-cement column", Journal of Central South University, Vol.22, No.7, (2015), pp.2699-2706 https://doi.org/10.1007/s11771-015-2800-7

[5] DSTU B V.2.7-187:2009 Budivelni materialy. Tsementy. Metody vyznachennia mitsnosti na zhyn i stysk.

[6] DSTU ISO 3696:2003 Voda dlia zastosuvannia v laboratoriiakh. Vymohy ta metody pereviriannia (ISO 3696:1987, IDT)
[7] DSTU B V.2.7-239:2010. Rozchyny budivelni. Metody vyprobuvan (EN 1015-11:1999, NEQ).

[8] N. L. Zotsenko, Yu. L. Vinnikov, "Long-Term Settlement of Buildings Erected on Driven Cast-In-Situ Piles in Loess Soil", Soil Mechanics and Foundation Engineering, Vol.53, No.3, (2016), pp.189-195, https://doi.org/10.1007/s11204-016-9384-6

[9] N. L. Zotsenko, N. I. Lapin, R. V. Petrash, "Comparative effectiveness of bed reinforcement based on plate tests and mathematical modeling", Soil Mechanics and Foundation Engineering, Vol.45, No.4, (2008), pp.138-143, https://doi.org/10.1007/s11204-0089014-z

[10] Shakti Suman, Mahasakti Mahamaya, Sarat Kumar Das, "Prediction of Maximum Dry Density and Unconfined Compressive Strength of Cement Stabilised Soil Using Artificial Intelligence Techniques", International Journal of Geosynthetics and Ground Engineering, Vol.2, No.2, (2016), pp.1-11, https://doi.org/10.1007/s40891-016-0051-9

[11] Popova, A.V., Kremenetsky, V.G., Solov'ev, V.V., Chernenko, L.A., Kremenetskaya, O.V., Fofanov, A.D., Kuznetsov, S.A., "Standard rate constants of charge transfer for $\mathrm{Nb}(\mathrm{V}) / \mathrm{Nb}(\mathrm{IV})$ redox couple in chloride-fluoride melts: Experimental and calculation methods", Russian Journal of Electrochemistry, Vol.46, No.6, (2010), pp.671-679, doi: 10.1134/S1023193510060121

[12] Victor Bondar, Volodymyr Shulgin, Oksana Demchenko, Ludmila Bondar, "Experimental study of properties of heavy concrete with bottom ash from power stations", MATEC Web of Conferences, Vol.116, No.02007, (2017). DOI: 10.1051/matecconf/20171160200 Transbud-2017 (Scopus) https://www.matec-conferences.org/ articles/matecconf/pdf/2017/30/matecconf_trs2017_02007.pdf 